\title{
Dimethylzinc-Mediated Addition of Phenylacetylene to a-Diketones Catalyzed by Chiral Perhydro-1,3-benzoxazines
}

\author{
Rebeca Infante, $^{\dagger}$ Jose M. Martin-Alvarez, $^{\ddagger}$ Celia Andrés* ${ }^{\dagger}$ and Javier Nieto* ${ }^{\dagger}$ \\ ${ }^{\dagger}$ Instituto CINQUIMA and Departamento de Química Orgánica, Facultad de Ciencias, Universidad de Valladolid, Paseo de \\ Belén, 7, 47011 Valladolid, Spain \\ ${ }^{\ddagger}$ Instituto CINQUIMA and Departamento de Química Inorgánica, Facultad de Ciencias, Universidad de Valladolid, Paseo de \\ Belén, 7, 47011 Valladolid, Spain
}

Supporting Information
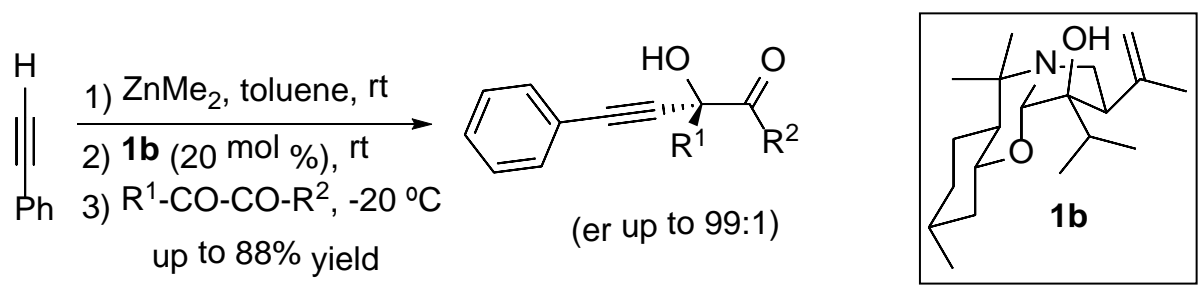

ABSTRACT: An efficient enantioselective $\mathrm{Me}_{2} \mathrm{Zn}$-mediated mono addition of phenylacetylene to $\alpha$-diketones in the presence of a chiral perhydro-1,3-benzoxazine ligand is described. At temperatures higher than $-20{ }^{\circ} \mathrm{C}$ a kinetic resolution of the resulting $\alpha$-hydroxy ketone occurs which greatly improves the enantioselectivity although with moderate chemical yield. The alkynylation of nonsymmetrical aromatic diketones with electronically different substituents on the aromatic rings proceed with high regioselectivity. This procedure allows the preparation of $\alpha$-hydroxy- $\alpha$-ynyl-ketones as highly enantioenriched materials.

Enantioenriched $\alpha$-hydroxy ketones are a particularly valuable class of chiral building blocks in organic synthesis, which are widely employed in the preparation of several bioactive molecules and natural products, ${ }^{1}$ as well as chiral auxiliaries for asymmetric synthesis. ${ }^{2}$ In addition, they can be used for the further formation of many other important structures as amino alcohols, diols or $\alpha$-hydroxy ethers. ${ }^{3}$ Various methods have been developed for the enantioselective synthesis of $\alpha$-hydroxy ketones including oxidation of enolates ${ }^{4}$ and enol ethers, ${ }^{5}$ the direct asymmetric $\alpha$-oxygenation of ketones in the presence of chiral catalyst, ${ }^{6}$ the asymmetric mono-oxidation of the correspondent 1,2-diols, ${ }^{7}$ the ketohydroxylation of olefins, ${ }^{8}$ the oxidative kinetic resolution of racemic $\alpha$-hydroxy ketones, ${ }^{9}$ the asymmetric hydrogenation of $\alpha$-diketones, ${ }^{10}$ the traditional benzoin condensation carried out stereoselectively by means of optically active catalysts ${ }^{11}$ as well as different biocatalytic strategies. $^{12}$

Although the mono-addition of organometellic reagents to $\alpha$-diketones produce tertiary $\alpha$-hydroxy carbonyl compounds not readily available by other routes, the asymmetric version of this reaction has been less studied and only some examples of rhodium-catalyzed asymmetric1,2-addition of arylboronic acids to $\alpha$-diketones have been reported. ${ }^{13}$ Over the past years, the asymmetric addition of organozinc reagents to aldehydes in the presence of chiral ligands has been one of the most useful approaches to the synthesis of secondary alcohols with high enantiomeric purity. ${ }^{14}$ By contrast the access to chiral tertiary alcohols enjoys limited success due to the low reactivity of these reagents toward the ketone carbonyl group and the difficulty in controlling facial stereoselectivity. More reactive ketones, such as $\alpha$-ketoesters, could be an advantage in terms of reactivity, although not for the enantiocontrol. Ketoesters can act as chelating ligands by itself and activate the organometallic reagent, which results in a strong background reaction. Because of that, scarce examples of catalytic asymmetric additions with a chiral ligand have been reported. ${ }^{15}$ Recently, we have shown that the conformationally restricted chiral perhydro-1,3-benzoxazines behave as excellent ligands for the enantioselective addition of organozinc derivatives to aldehydes and $\alpha$-keto esters, ${ }^{16}$ and in this way we envisioned their utilization as ligands for the enantioselective mono-alkynylation of $\alpha$-diketones. ${ }^{17,18}$ To the best of our knowledge, no successful examples of enantioselective addition of organozinc derivatives to $\alpha$-diketones are known. The resulting enantioenriched $\alpha$-hydroxy $\alpha$-alkynyl carbonyl compounds are interesting chiral highly functionalized building blocks for organic synthesis. $^{19,20}$

We first screened a series of easily prepared 1,3benzoxazines 1a-f ${ }^{21}$ as chiral ligands (20 mol \%) in the model reaction of 1,2-diphenylethane-1,2-dione 2a with the alkynylzinc derivative prepared from phenylacetylene and dimethylzinc in toluene at room temperature and the results are collected in Table 1 . The reaction of diketone $\mathbf{2 a}$ with the alkynylzinc derivative in the presence of most of these ligants afforded the product of mono-alkynylation 3a in low to moderate enantioselectivity (Table 1, entries 1, 3-6). Interestingly, the benzoxazine 1b stood out with much higher efficiency 
than the others (Table 1, entry 2) (96:4 er). In all cases the chemical yield was low. The structure of chiral ligand $\mathbf{1 e}$ is similar to $\mathbf{1 b}$ but provided poor enantioselectivity (Table 1, entry 5) (67:33 er). Both $\mathbf{1 b}$ and $\mathbf{1 e}$ possess a bulky isopropyl group on the tertiary stereocenter on the carbon that bears the hydroxy group. The difference between $\mathbf{1 b}$ and $\mathbf{1 e}$ is the former bears an additional isopropenyl substituent, the latter another isopropyl substituent. The sterically less hindered isopropenyl of $\mathbf{1 b}$ seems more suitable for enantioselective reaction. The 1,2-isopropyl di-substituents of 1e would be too crowded. In all cases the starting diketone 2a was completely consumed but secondary reactions occurs in the reaction conditions tested and a complex mixture of unidentified products together with the desired $\alpha$-hydroxyketone 3a was formed. With the best ligand in hand, in the subsequent studies we turned our attention to the other reaction parameters including reaction temperatures, reaction times, solvents and catalyst loadings. Surprisingly, reaction temperature seems to play an adverse effect on the enantioselectivity. When the temperature was decreased from $0{ }^{\circ} \mathrm{C}$ to $-10^{\circ} \mathrm{C}$, the isolated yields were improved from $35 \%$ to $76 \%$ whilst the enantioselectivity declined from 96:4 to 92:8 er (Table 1, compare entry 7 versus entry 2), nevertheless at $-20{ }^{\circ} \mathrm{C}$ the isolated yield and the enantiomeric excess again improved (Table 1, entry 8) ( 88\%; 94:6 er). To explain these observations a more detailed study of the evolution of the reaction with time at different temperatures was carried out [see also the Supporting Information (SI)]. At $0{ }^{\circ} \mathrm{C}$ the reaction was fast, after $30 \mathrm{~min}$ 3a was isolated in a $59 \%$ of chemical yield and 87:13 er (Table 1, entry 10). At $2 \mathrm{~h}$ and $15 \mathrm{~min}$ the enantioselectivity improved slightly (Table 1, entry 11) (89:11 er) and the chemical yield was $70 \%$, only traces of starting material 2a were observed in the ${ }^{1} \mathrm{H}$ NMR spectra of the reaction mixture. At $6 \mathrm{~h}$ and $30 \mathrm{~min}$ the chemical yield of the isolated product $3 \mathbf{a}$ decreased to $40 \%$, although the enantioselectivity improved to 92:8 er (Table 1, entry 12). Even an enantioselectivity greater than 99:1 er was reached after $48 \mathrm{~h}$ of reaction, although only a $18 \%$ of $3 \mathbf{a}$ was isolated (Table 1, entry 13). These results indicate that a kinetic resolution takes place on the reaction product at $0{ }^{\circ} \mathrm{C}$ due to the overaddition of the organometallic species to the $\alpha$-hydroxy ketone, ${ }^{22}$ This process also occurs at $-10{ }^{\circ} \mathrm{C}$, but at $-20{ }^{\circ} \mathrm{C}$ is slow enough so that hydroxy ketone 3a to be isolated in $88 \%$ of chemical yield at $20 \mathrm{~h}$ of reaction and no variation of the enantioselectivity was observed during this period (see SI).

Solvent effects were also probed at $-20^{\circ} \mathrm{C}$ (Table 1 , entries 15 17) and it was found that toluene was ideal for this process. In $\mathrm{CH}_{2} \mathrm{Cl}_{2}$ the enantioselectivity was similar but the chemical yield decrease. In hexane 2 a was poorly soluble at $-20{ }^{\circ} \mathrm{C}$ while in ethereal solvents the results were very poor in terms of enantioselectivity. On the other hand, catalyst loadings also had a significant effect on the enantioselectivity. A considerable decrease in the enantioselectivity was perceived when the catalyst loading was reduced to $10 \mathrm{~mol} \%$ (Table 1, entry 19), although the use of $15 \mathrm{~mol} \%$ resulted in a very competitive 93:7 er (Table 1, entry 18). In addition, the use of 2 equiv of phenylacetylene and dimethylzinc instead of 4 equiv resulted in a much slower reaction and poor chemical yield.

After determining the optimal reaction conditions (4 equiv of phenylacetylene and dimethylzinc, $20 \mathrm{~mol} \%$ of $\mathbf{1 b}$ as ligand, at $-20^{\circ} \mathrm{C}$ in toluene for $20 \mathrm{~h}$ ), the substrate scope was explored
Table 1. Screening studies of enantioselective addition of phenylacetylene to 1,2-diphenylethane-1,2-dione $2 a^{a}$

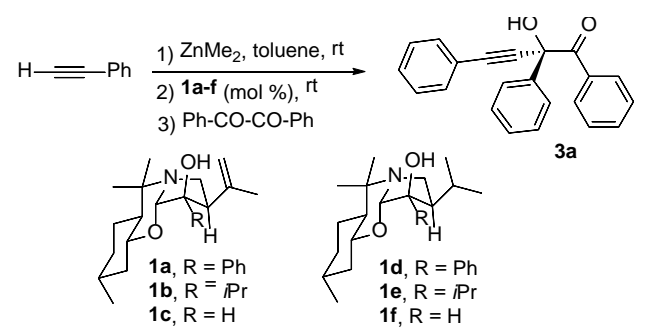

\begin{tabular}{ccccccc} 
entry & $\begin{array}{c}\text { ligand } \\
(\text { mol \%) }\end{array}$ & solvent & $t\left({ }^{\circ} \mathrm{C}\right)$ & $\begin{array}{c}\text { time (h) } \\
\text { yield }^{\mathrm{b}}\end{array}$ & $\mathrm{er}^{\mathrm{c}}$ \\
\hline 1 & $\mathbf{1 a}(20)$ & toluene & 0 & 20 & 44 & $84: 16$ \\
2 & $\mathbf{1 b}(20)$ & toluene & 0 & 20 & 33 & $96: 4$ \\
3 & $\mathbf{1 c}(20)$ & toluene & 0 & 20 & 42 & $46: 54$ \\
4 & $\mathbf{1 d}(20)$ & toluene & 0 & 20 & 36 & $79: 21$ \\
5 & $\mathbf{1 e}(20)$ & toluene & 0 & 20 & 40 & $67: 33$ \\
6 & $\mathbf{1 f}(20)$ & toluene & 0 & 20 & 50 & $49: 51$ \\
7 & $\mathbf{1 b}(20)$ & toluene & -10 & 20 & 76 & $92: 8$ \\
8 & $\mathbf{1 b}(20)$ & toluene & -20 & 20 & 88 & $94: 6$ \\
9 & $\mathbf{1 b}(20)$ & toluene & -30 & 30 & $70^{\mathrm{d}}$ & $94: 6$ \\
10 & $\mathbf{1 b}(20)$ & toluene & 0 & 0.5 & $59^{\mathrm{d}}$ & $87: 13$ \\
11 & $\mathbf{1 b}(20)$ & toluene & 0 & 2.25 & 70 & $89: 11$ \\
12 & $\mathbf{1 b}(20)$ & toluene & 0 & 6.5 & 40 & $92: 8$ \\
13 & $\mathbf{1 b}(20)$ & toluene & 0 & 48 & 18 & $>99: 1$ \\
14 & $\mathbf{1 b}(20)$ & hexane & -20 & 20 & $15^{\mathrm{d}}$ & --- \\
15 & $\mathbf{1 b}(20)$ & CH ${ }_{2} \mathrm{Cl}{ }_{2}$ & -20 & 20 & $68^{\mathrm{d}}$ & $92: 8$ \\
16 & $\mathbf{1 b}(20)$ & THF & -20 & 20 & 66 & $77: 23$ \\
17 & $\mathbf{1 b}(20)$ & Et ${ }_{2} \mathrm{O}$ & -20 & 20 & $56^{\mathrm{d}}$ & $65: 35$ \\
18 & $\mathbf{1 b}(15)$ & toluene & -20 & 20 & 84 & $93: 7$ \\
19 & $\mathbf{1 b}(10)$ & toluene & -20 & 20 & 80 & $89: 11$ \\
20 & $\mathbf{1 b}(20)^{\mathrm{e}}$ & toluene & -20 & 30 & $58^{\mathrm{d}}$ & $92: 8$
\end{tabular}

${ }^{a}$ Reaction conditions: $0.15 \mathrm{mmol}$ (1.0 equiv) of 2a, $0.6 \mathrm{mmol}$ (4.0 equiv) of dimethylzinc and $0,63 \mathrm{mmol}$ (4.2 equiv) of phenylacetylene. ${ }^{b}$ Yield of isolated product after purification by flash column chromatography. ${ }^{c}$ Enantiomeric ratio determined by HPLC on a chiral stationary phase (see SI). ${ }^{d}$ Variable amounts of the starting diketone 2a were recovered. ${ }^{e}$ Only $0.3 \mathrm{mmol}$ of dimethylzinc (2.0 equiv) and $0.31 \mathrm{mmol}$ (2.1 equiv) of phenylacetylene was used.

in the alkynylation of a series of aromatic and aliphatic $\alpha$ diketones, and the results are collected in Scheme 2.

The enantiocontrol seemed not to be influenced by electronic or steric effects and the alkynylation of diverse ortho, meta and para-substituted aromatic $\alpha$-diketones was promoted with good enantioselectivity. Electron-donating (diketones 2b-d) and electron-withdrawing substituents (diketones 2e-g) were tolerated in the aromatic ring without significant changes of the selectivity. Even a more bulky diketone such as the 2-naphthyl $2 \mathbf{i}$ was alkynylated although with a somewhat more moderate chemical yield and selectivity (62\%, 89:11 er). The scope of the reaction was further explored and heteroaromatic $\mathbf{2 h}$ and enolizable aliphatic $\mathbf{2} \mathbf{j}$ and $\mathbf{2 k}$ diketones were subjected to the alkynylation protocol. 
Scheme 1. Substrate scope of the alkynylation of 1,2diketones $2 \mathrm{a}-\mathbf{j}{ }^{a}$

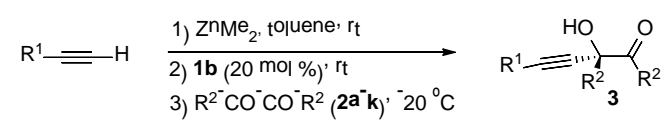
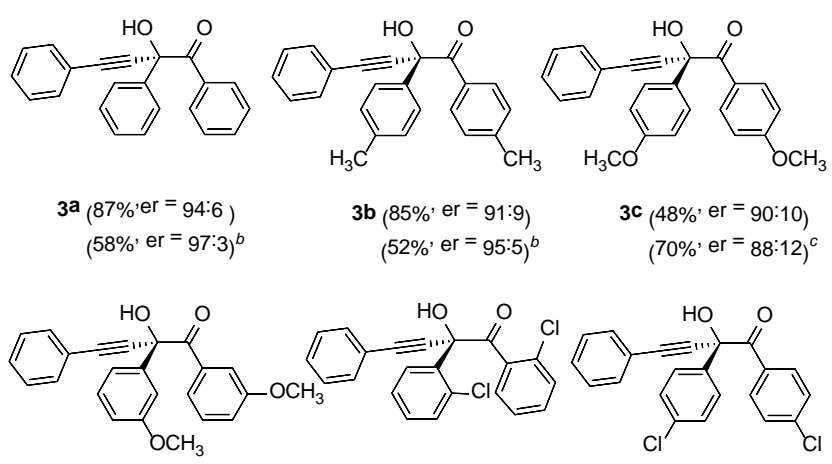

$$
\text { 3d }(85 \% \text {, er }=92: 8) \quad \text { 3e }(83 \%, \text { er }=88: 12) \quad \text { 3f }(69 \%, \text { er }=97: 3)^{c}
$$
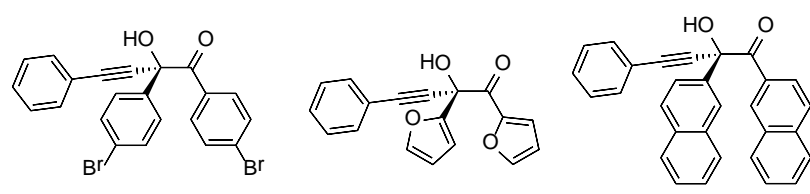

$3 g(48 \%, \text { er }=93: 7)^{c}$ 3h $(77 \%$, er $=97: 3)$
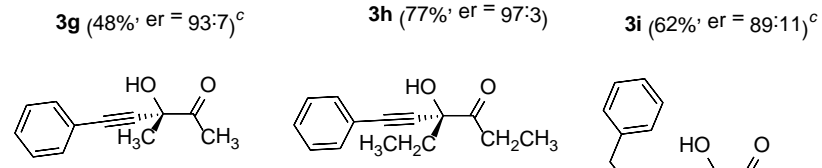

$3 \mathbf{j}(68 \%$, er $=99: 1)$

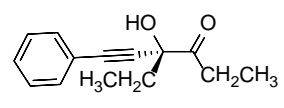

$3 \mathbf{k}(72 \%$, er >99:1)
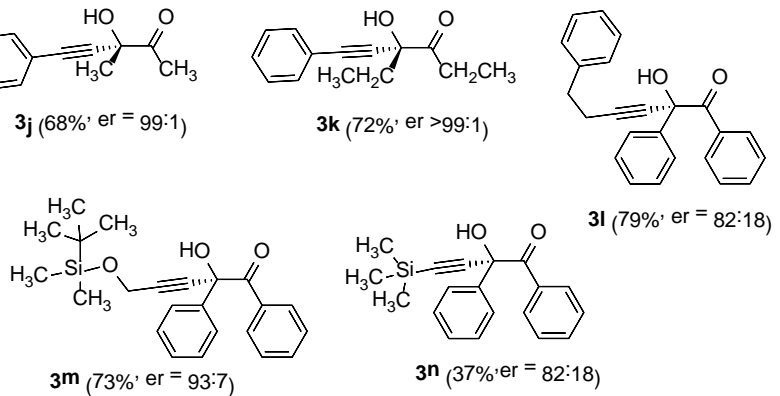

${ }^{a}$ Reaction conditions: 1) alkyne 1.05 mmol (4.2 equiv), 1.0 mmol (4.0 equiv) of dimethylzinc,toluene rt, 1 h. 2) Ligand $\mathbf{1 b}$ $0.05 \mathrm{mmol}$ ( $20 \mathrm{~mol} \%, 0.2$ equiv), toluene, rt, $30 \mathrm{~min}$. 3) Diketone (2a, $\mathrm{R}^{2}=\mathrm{C}_{6} \mathrm{H}_{5} ; \mathbf{2} \mathbf{b}, \mathrm{R}^{2}=p-\mathrm{CH}_{3}-\mathrm{C}_{6} \mathrm{H}_{4} ; 2 \mathbf{c}, \mathrm{R}^{2}=p-\mathrm{OCH}_{3}-\mathrm{C}_{6} \mathrm{H}_{4}$; 2d, $\mathrm{R}^{2}=m-\mathrm{OCH}_{3}-\mathrm{C}_{6} \mathrm{H}_{4} ; 2 \mathbf{2 e}, \mathrm{R}^{2}=o-\mathrm{Cl}-\mathrm{C}_{6} \mathrm{H}_{4} ; 2 \mathbf{2 f}, \mathrm{R}^{2}=p-\mathrm{Cl}-$ $\mathrm{C}_{6} \mathrm{H}_{4} ; 2 \mathrm{~g}, \mathrm{R}^{2}=p$ - $\mathrm{Br}^{-} \mathrm{C}_{6} \mathrm{H}_{4} ; \mathbf{2 h}, \mathrm{R}^{2}=2$-furyl; 2i, $\mathrm{R}^{2}=$ 2-napthyl; $\left.2 \mathbf{j}, \mathrm{R}^{2}=\mathrm{CH}_{3} ; 2 \mathbf{k}, \mathrm{R}^{2}=\mathrm{CH}_{2} \mathrm{CH}_{3}\right) \quad 0.25$ mmol (1.0 equiv), toluene, $-20{ }^{\circ} \mathrm{C}, 20 \mathrm{~h} .{ }^{b}$ Reaction was stirring additional $4 \mathrm{~h}$ at 0 ${ }^{\circ} \mathrm{C}$. ${ }^{C}$ Diketone 2 was dissolved and added in $\mathrm{CH}_{2} \mathrm{Cl}_{2}$.

Products $\mathbf{3 h}, \mathbf{3 j}$ and $\mathbf{3 k}$, respectively, were delivered with selectivities greater than $97: 3$ er.

The diketones $\mathbf{2 c}, \mathbf{2 f}, \mathbf{2} \mathbf{g}$ and $\mathbf{2} \mathbf{i}$ were dissolved in dichloromethane for addition on the alkynyl zinc because of their insolubility in toluene at $-20^{\circ} \mathrm{C}$. The enantioselectivity for the alkynylation ketone 2c was slightly lower in dichloromethane than in toluene (88:12 versus 90:10 er) as in the case of ketone 2a (see entries 15 versus 8 in Table 1).

To test the generality of this reaction respect to the alkyne, alkynylation of diketone 2a with the aliphatic terminal alkynes 4-phenyl-1-butyne and 3-(tert-butyldimethylsilyloxy)-1propyne was also performed. The corresponding $\alpha$-hydroxy ketones $\mathbf{3 l}$ and $\mathbf{3 m}$ were isolated with good chemical yields. However, when trimethylsilylacetylene was used as terminal alkyne, the $\alpha$-hydroxy ketone 3 n was obtained in only a $37 \%$.

The enantioselectivity was good for $\mathbf{3 m}$ but moderate for $\mathbf{3 l}$ and $3 \mathbf{n}$.

On the other hand, enantioselectivity can be improved although at the expense of a significant loss of chemical yield if once the hydroxyl ketones $\mathbf{3}$ were formed at $-20^{\circ} \mathrm{C}$, the kinetic resolution is allowed to occur at $0{ }^{\circ} \mathrm{C}$ for $4 \mathrm{~h}$. In this way the hydroxyketones $\mathbf{3} \mathbf{a}$ and $\mathbf{3 b}$ were prepared with an enantioselectivity of 97:3 and 95:5 er respectively.

In order to increase the substrate generality we decided to explore the regio- and enantioselectivity in the alkynylation of nonsymmetrical diketones (Scheme 2).

To our delight, the alkynylation of aromatic diketones with electronically different substuents on the aromatic rings proceed with high regioselectivity. As expected, the alkynylation of diketone 2o with an electron-donating methoxy group on one of the aromatic ring and an electron-withdrawing chlorine on the other occurs preferably on the carbonyl group attached to the ring with the withdrawing group. After $20 \mathrm{~h}$ of reaction at $-20{ }^{\circ} \mathrm{C}$ a mixture of hydroxy ketones 30 and 40 were obtained in a ratio $93: 7$ and $72 \%$ of chemical yield. The enantioselectivity for mayor product 30 was 92:8 er. When the reaction was stirred four additional 4 hours at $0^{\circ} \mathrm{C}$ minor hydroxy ketone 40 was no observed in the ${ }^{1} \mathrm{H}$ NMR spectra of the reaction mixture and 30 was isolated in a $48 \%$ of chemical yield and a 96:4 er. On the other hand, alkynylation of diketone 2p with two methoxy groups in one of the aromatic rings proceeded with total regioselectivity and only the formation of hydroxy ketone 3p (95:5 er) was observed in the

Scheme 2. Substrate scope of the alkynylation of 1,2diketones 2o-q. ${ }^{a}$

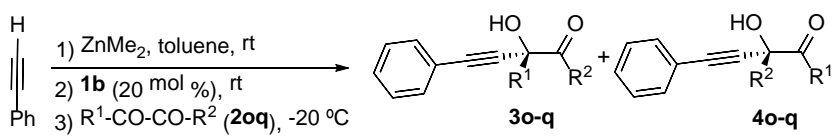

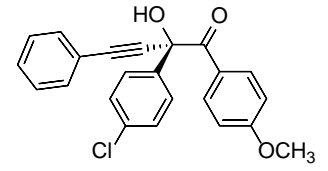

$30(67 \%$, er $=92: 8)$

$(48 \%, \text { er }=96: 4)^{b}$

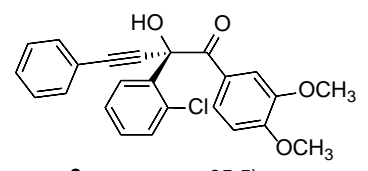

$3 \mathbf{p}(72 \%$, er $=95: 5)$

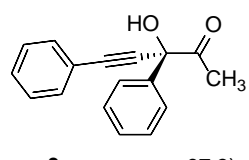

3q $(39 \%$, er $=97: 3)$

$$
\text { (n) }
$$

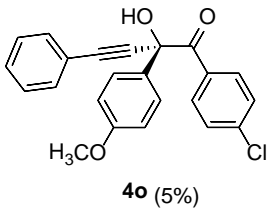

$40(5 \%)$

$$
\text { (1) }
$$
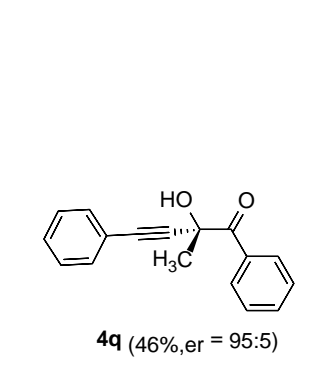

${ }^{a}$ Reaction conditions: 1) phenylacetylene $1.05 \mathrm{mmol}$ (4.2 equiv), $1.0 \mathrm{mmol}$ (4.0 equiv) of dimethylzinc, toluene rt, $1 \mathrm{h.} \mathrm{2}$ ) Ligand $1 \mathbf{b} 0.05 \mathrm{mmol}$ ( $20 \mathrm{~mol} \%, 0.2$ equiv), toluene, rt, $30 \mathrm{~min}$. 3) Diketone (2o, $\mathrm{R}^{1}=p-\mathrm{Cl}-\mathrm{C}_{6} \mathrm{H}_{4}, \mathrm{R}^{2}=p-\mathrm{OCH}_{3}-\mathrm{C}_{6} \mathrm{H}_{4} ; 2 \mathrm{p}, \mathrm{R}^{1}=$ p-Cl- $\left.\mathrm{C}_{6} \mathrm{H}_{4}, \mathrm{R}^{2}=3,4-\left(\mathrm{OCH}_{3}\right)_{2}-\mathrm{C}_{6} \mathrm{H}_{4}, 2 \mathbf{q}, \mathrm{R}^{1}=\mathrm{C}_{6} \mathrm{H}_{5}, \mathrm{R}^{2}=\mathrm{CH}_{3}\right)$ $0.25 \mathrm{mmol}$ (1 equiv), toluene, $-20{ }^{\circ} \mathrm{C}, 20 \mathrm{~h} .{ }^{b}$ Reaction was stirring additional $4 \mathrm{~h}$ at $0{ }^{\circ} \mathrm{C}$. 
${ }^{1} \mathrm{H}$ NMR spectra of the reaction mixture after $20 \mathrm{~h}$ of reaction at $-20^{\circ} \mathrm{C}$. However, the alkynylation of the alkyl aryl diketone $\mathbf{2 q}$ provided a mixture of hydroxy ketones $\mathbf{3 q}$ and $\mathbf{4 q}$ without regioselectivity althougt with high enantioselectivity (97:3 er for $\mathbf{3 q}$ and 95:5 er for $\mathbf{4 q}$ ).

The configuration of the newly formed stereogenic center of 30 was established by X-ray diffraction analysis ${ }^{23}$ and has been extended to all the other hydroxyketones 3a-q, $\mathbf{4 0}$ and $\mathbf{4 q}$ based on mechanistic analogy.

Finally, in order to investigate the mechanism of kinetic resolution of the resulting $\alpha$-hydroxy- $\alpha$-ynyl-ketones we centered our attention in the alkynylation of aliphatic diketone $\mathbf{2 j}$. A detailed monitoring of reaction of $2 \mathbf{j}$ showed that for aliphatic diketones kinetic resolution occurs at $-20{ }^{\circ} \mathrm{C}$ (see the Supporting Information). The only byproducts formed in the reaction were the meso diol $5 \mathbf{j}$ and the chiral diol $\mathbf{6 j}$ (Figure 1) generated by a second addition of the alkynyl zinc derivative to the $\alpha$-hydroxy ketone. In the reaction conditions the minor $R$-enantiomer of the hydroxy ketone $\mathbf{3 j}$ reacts faster than the major $S$-enantiomer and the enantioselectivity of $\mathbf{3} \mathbf{j}$ improves but the chemical yield decreases.
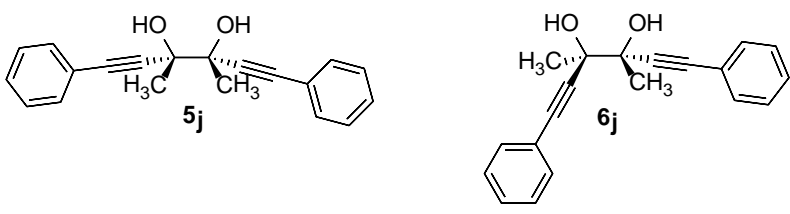

Figure 1. Structures of diols $5 \mathbf{j}$ and $\mathbf{6 j}$.

In conclusion, we have developed an efficient enantioselective phenylacetylene addition to $\alpha$-diketones in the presence of $\mathrm{ZnMe}_{2}$ using a chiral perhydro-1,3-benzoxazine ligand. This process provided a convenient method to access enantioenriched $\alpha$-hydroxy- $\alpha$-ynyl-ketones.

\section{ASSOCIATED CONTENT}

\section{Supporting Information}

The Supporting Information is available free of charge on the ACS Publications website.

Detailed experimental procedures, characterization data, copies of the ${ }^{1} \mathrm{H}$ and ${ }^{13} \mathrm{C}$ NMR spectra, and copies of the chromatograms for all new products (PDF).

Crystallographic file for compound $3 \mathbf{o}$ (CIF).

\section{AUTHOR INFORMATION}

\section{Corresponding Authors}

* javiernr@qo.uva.es

* celian@qo.uva.es

\section{ORCID}

Javier Nieto: 0000-0002-5655-3320

\section{ACKNOWLEDGMENT}

We acknowledge the financial support provided by the Spanish MINECO (Project CTQ2014-59870 P) and Junta de Castilla y León (Project VA064U13).

\section{REFERENCES}

(1) (a) Fang, Q. K.; Han, Z.; Grover, P.; Kessler, D.; Senanayake, C. H.; Wald, S. A. Tetrahedron: Asymmetry 2000, 11, 3659-3663. (b) Wildemann, H.; Dünkelmann, P.; Müller, M.; Schmidt, B. J. Org. Chem. 2003, 68, 799-804. (c) Wallace, O. B.; Smith, D. W.; Deshpande, M. S.; Polson, C.; Felsenstein, K. M. Bioorg. Med. Chem.Lett. 2003, 13, 1203-1206. (d) Andrus, M. B.; Hicken, E. J.; Stephens, J. C.; Bedke, D. K. J. Org. Chem. 2006, 71, 8651-8654.

(2) Palomo, C.; Oiarbidea, M.; García, J. M. Chem. Soc. Rev. 2012, 41, 4150-4164

(3) Davis, F. A.; Haque, M. S.; Przeslawski, R. M. J. Org. Chem. 1989, 54, 2021-2024.

(4) (a) Davis, F. A.; Chen, B. C.; Chem. Rev. 1992, 92, 919-934. (b) Momiyama, N.; Yamamoto, H. J. Am. Chem. Soc. 2003, 125, 6038-6039.

(5) (a) Hashiyama, T.; Morikawa, K.; Sharpless, K. B. J. Org. Chem. 1992, 57, 5067-5068. (b) Kawasaki, M.; Li, P. F.; Yamamoto, H. Angew. Chem., Int. Ed. 2008, 47, 3855-3857. (c) Yanagisawa, A.; Takeshita, S.; Izumi, Y.; Yoshida, K. J. Am. Chem. Soc. 2010, 132, 5328-5329.

(6) (a) Bøgevig, A.; Sundén, H.; Córdova, A. Angew. Chem. Int. Ed. 2004, 43, 1109-1112. (b) Hayashi, Y.; Yamaguchi, J.; Sumiya, T.; Shoji, M. Angew. Chem. Int. Ed. 2004, 43, 1112-115. (c) Ramachary, D. B.; Barbas III, C. F. Org. Lett. 2005, 7, 1577-1580.

(7) (a) Adam, W.; Saha-Möller, C. R.; Zhao, C.-G. J. Org. Chem. 1999, 64, 7492-7497. (b) Müller, C. E.; Hrdina, R.; Wende, R. C.; Schreiner, P. R. Chem Eur. J. 2011, 17, 6309-6214.

(8) Plietker, B. Org. Lett. 2004, 6, 289-291.

(9) (a) Alamsetti, S. K.; Muthupandi, P.; Sekar, G. Chem. Eur. J. 2009, 15, 5424-5427. (b) Chen, C.-T.; Kao, J.-Q.; Salunke, S. B.; Lin, Y.-H. Org. Lett. 2011, 13, 26-29.

(10) (a) Koike, T.; Murata, K.; Ikariya, T. Org. Lett. 2000, 2, 38333836. (b) Sun, T.; Zhang, X.; Adv. Synth Catal. 2012, 354, 32113215.

(11) (a) Enders, D.; Niemeier, O.; Henseler, A. Chem. Rev. 2007, 107, 5606-5655. (b) Bugaut, X.; Glorius, F. Chem. Soc. Rev. 2012, 41, 3511-3522.

(12) (a) Adam, W.; Lazarus, M.; Saha-Möller, C. R.; Schreier, P.; Acc. Chem. Res. 1999, 32, 837-845. (b) Hoyos, P.; Sinisterra, J-V.; Molinari, F.; Alcántara, A. R.; Domínguez de María, P.; Acc. Chem. Res. 2010, 43, 288-299.

(13) (a) Feng, X.; Nie, Y.; Yang, J.; Du, H. Org. Lett. 2012, 14, 624-627. (b) Zhu, T.-S.; Jin, S.-S.; Xu, M.-H. Angew. Chem. Int. Ed, 2012, 51, 780-783. (c) Zhu, T.-S.; Chen, J.-P.; Xu, M.-H. Chem. Eur. J. 2013, 19, 865-869.

(14) (a) Soai, K.; Niwa, S. Chem. Rev. 1992, 92, 833-856. (b) Pu, L.; Yu, H.-B. Chem. Rev. 2001, 101, 757-824.

(15) (a) Funabashi, K.; Jachmann, M.; Kanai, M.; Shibasaki, M. Angew. Chem. Int. Ed. 2003, 42, 5489-5492. (b) Wieland, L. C.; Deng, H.; Snapper, M. L.; Hoveyda, A. H. J. Am. Chem. Soc. 2005, 127, 15453-15456. (c) Blay, G.; Fernandez, I.; Marco-Aleixandre, A.; Pedro, J. R. Org. Lett. 2006, 8, 1287-1290. (d) Wu, H.-L.; Wu, P.-Y.; Shen, Y.-Y.; Uang, B.-J. J. Org. Chem. 2008, 73, 6445-6447.

(16) (a) Andrés, C.; Infante, R.; Nieto, J. Tetrahedron: Asymmetry 2010, 21, 2230-2237. (b) Infante, R.; Nieto, J.; Andrés, C. Org. Biomol. Chem. 2011, 9, 6691-6699. (c) Infante, R.; Nieto, J.; Andrés, C. Synthesis 2012, 44, 1343-1348. (d) Infante, R.; Nieto, J.; Andrés, C. Chem. Eur. J. 2012, 18, 4375-4379. (e) Infante, R.; Gago, A.; Nieto, J.; Andrés, C. Adv. Synth. Catal. 2012, 354, 2797-2804.

(17) For a review of enantioselective addition of alkyne nucleophiles to carbonyl groups see: Trost, B. M.; Weiss, A. H. Adv. Synth. Catal. 2009, 351, 963-983.

(18) For recent examples of enantioselective alkynylation of activated ketones see: (a) Jiang, B.; Chen, Z.; Tang, X.; Org. Lett. 2002, 4, 3451-3453. (b) Aikawa, K.; Hioki, Y.; Mikami, K. Org. Lett. 2010, 12, 5716-5719. (c) Ohshima, T.; Kawabata, T.; Takeuchi, Y.; Kakinuma, T.; Iwasaki, T.; Yonezawa, T.; Murakami, H.; Nishiyama, H.; Mashima, K. Angew. Chem. Int. Ed. 2011, 50, 6296-6300.

(19) For a recent example of enantioselective synthesis of $\alpha$ hydroxy $\alpha$-alkynyl carbonyl compounds see: Sánchez-Díez, E., Fer- 
nández, M.; Uria, U.; Reyes, E.; Carrillo, L.; Vicario, J. L., Chem. Eur. J. 2015, 21, 8384-8388.

(20) An interesting addition of alkynes to $\alpha$-diketones catalyzed by rhodium-phosphine complex has been described, but the use of chiral phosphines to induce asymmetry in the products provided low enantioselectivity: Dhondi, P. K.; Carberry, P.; Choi, L. B.; Chisholm, J. D. J. Org. Chem. 2007, 72, 9590-9596.

(21) (a) Pedrosa, R.; Andrés, C.; Rosón, C. D.; Vicente, M. J. Org. Chem. 2003, 68, 1852-1858. (b) Andrés, C.; González, I.; Nieto, J.; Rosón, C. D. Tetrahedron 2009, 65, 9728-9736.
(22) This behaviour has also been previously described in the alkynylation of $\alpha$-ketoesters: Chen, H.-B.; Lai, W.-H.; Zhao, Y.; Qin, D.-D.; Ruan, Y.-P.; Zhou, Z.-H. Synlett 2014, 25, 809-812.

(23) See the Supporting Information for details. CCDC 1523500 contains the supplementary crystallographic data for this paper. These data can be obtained free of charge from The Cambridge Crystallographic Data Centre via www.ccdc.cam.ac.uk/data_request/cif. 